REVESCO. Revista de Estudios Cooperativos

ISSN: $1885-8031$

http://dx.doi.org/10.5209/REVE.57065

\title{
Responsabilidad Social en las empresas de Economía Social: un análisis comparativo del tejido productivo de la Comunidad Valenciana
}

\author{
Antonia Sajardo-Moreno ${ }^{1}$ y Rafael J. Chaves-Sajardo ${ }^{2}$
}

Recibido: 16 de abril de 2017 / Aceptado: 17 de julio de 2017

Resumen. Este trabajo realiza un análisis de las prácticas de Responsabilidad Social Empresarial (RSE) interna de las empresas de Economía Social en la Comunidad Valenciana, y su comparativa con el conjunto de empresas de la Comunidad. A través del citado análisis se pretende ofrecer evidencia empírica para fundamentar el superior compromiso de las empresas de Economía Social con su entorno laboral, medioambiental, con sus grupos de interés y con el Buen Gobierno. La literatura académica al respecto, centrada básicamente en el ámbito de las cooperativas, ha venido constatando cómo la propia naturaleza y principios de actuación de las empresas de Economía Social constituyen el substrato básico de una empresa socialmente responsable. Y es que los fundamentos de la RSE se hallan en el seno mismo de las empresas de Economía Social, al incorporar una cultura participativa y unas pautas de actuación conciliadoras de la dimensión económica y social. En estas empresas se generan unos vínculos y valores sociales superiores a cualquier otro tipo de empresas, y por lo tanto cuentan con mayor potencial para la adopción de prácticas de RSE. Este trabajo concluye mostrando como las empresas de Economía Social valenciana son superiormente responsables en todos los ítems que integra la RSE interna, con diferenciales positivos superiores en 8 puntos porcentuales, salvo en el área de Buen Gobierno, donde son superadas por el total de empresas de la Comunidad. Tales resultados forman parte de un estudio financiado por la Dirección General de Economía Social y emprendimiento de la Generalitat Valenciana, que tuvo como objetivo analizar las prácticas de Responsabilidad Social Empresarial del tejido productivo de la citada Comunidad.

Palabras clave: Economía Social; Responsabilidad Social Empresarial; Inversión Socialmente Responsable; Códigos de Buen Gobierno; Compromiso con el medioambiente; Planes de igualdad; Control de la cadena de proveedores; Medidas de información al consumidor.

Claves Econlit: M14; L31.

\section{[en] Social responsibility in social economy companies: a comparative analysis of the productive fabric of the Valencian Community}

Abstract. This work analyzes the Internal Social Responsibility (CSR) practices of Social Economy companies in the Valencian Community, and their comparison with the set of companies in the Community. Through this analysis, we intend to provide empirical evidence to support the superior commitment of Social Economy companies to their work environment, their environment, their stakeholders and Good Governance. The academic literature on this subject, centered mainly on the

1 Profesora Titular de Universidad. Departamento de Economía Aplicada. Universitat de València, España

Dirección de correo electrónico: antonia.sajardo@uv.es

2 Graduado en Negocios Internacionales por la Universitat de València, España 
field of cooperatives, has been observing how the very nature and principles of action of Social Economy companies constitute the basic substrate of a socially responsible company. And is that the foundations of CSR are in the very heart of Social Economy companies, incorporating a participatory culture and guidelines for action that are reconciling the economic and social dimension. In these companies, links and social values are generated that are superior to any other type of company, and therefore have greater potential for the adoption of CSR practices. This paper concludes by showing how the Valencian Social Economy companies are uppermost responsible in all the items that integrate the internal RSE, with superior positive differentials in 8 percentage points, except in the area of Good Government, where they are surpassed by the total of companies of community. These results are part of a study funded by the Directorate General of Social Economy and entrepreneurship of the Generalitat Valenciana, which aimed to analyze the practices of Corporate Social Responsibility of the productive fabric of the Community.

Keywords: Social Economy; Corporate Social Responsibility; Socially Responsible Investment; Codes of Good Governance; Commitment to the environment; Equality plans; Supplier chain control; Consumer information measures.

Sumario. 1. Introducción. 2. Revisión de la literatura. 3. Metodología del trabajo de campo. 4. El compromiso de las empresas valencianas de economía social con su entorno laboral. 5. El compromiso de las empresas valencianas de economía social con el medio ambiente. 6. El compromiso de las empresas valencianas de economía social con sus grupos de interés. 7. Las prácticas de buen gobierno en las empresas valencianas de economía social. 8. A modo de conclusión. 9. Referencias bibliográficas.

Cómo citar: Sajardo-Moreno, A. y Chaves-Sajardo, R.J. (2017) Responsabilidad Social en las empresas de Economía Social: un análisis comparativo del tejido productivo de la Comunidad Valenciana. REVESCO. Revista de Estudios Cooperativos, $\mathrm{N}^{\mathrm{o}}$ 125, pp. 213-242. DOI: 10.5209/REVE.57065.

\section{Introducción}

La Comisión Europea en el denominado Libro Verde, concibe a la Responsabilidad Social Empresarial (RSE, en adelante) como “...la integración voluntaria por parte de las empresas, de las preocupaciones sociales y ambientales en sus operaciones empresariales, y sus relaciones con sus interlocutores" (Comisión Europea, 2001).

La Economía Social (ES, en adelante), no es para nada ajena a este concepto, al contrario, ya que su propia lógica de funcionamiento, basada en la democracia, la justicia y el pleno desarrollo integral del hombre, la hacen especialmente proclive a las prácticas responsables. Y es que la ES conforma un espacio de actuación económica donde se produce un reemplazo del interés particular por el social, de los principios mercantiles de representación de la voluntad societaria por democracia y autogestión, y la aparición de finalidades más allá de las puramente económicas (CEPES, 2007).

De esta manera los fundamentos de la RSE se hallan en el seno mismo de las empresas de ES, al incorporar una cultura participativa y unas pautas de actuación conciliadoras de la dimensión económica y social (Social Economy in Europe, 2015). En idéntico sentido CEPES (2009), señala que la RSE no es ajena a la ES como estrategia empresarial, puesto que existen coincidencias entre los valores de las empresas de ES y los valores que promueve la RSE. El Parlamento Europeo (2009), en el denominado Informe Toia, ya explicitaba que las empresas de ES 
facilitan un mejor funcionamiento democrático del mundo de la empresa e incorporan claramente a la RSE.

La propia Ley 5/2011 de ES española reconoce y visualiza los valores sociales de la ES, tales como la primacía de las personas y el fin social sobre el capital, así como el compromiso con el desarrollo local, la cohesión y la sostenibilidad. Ello no hace sino reconocer, pública y socialmente, la íntima conexión existente entre las empresas de ES y la existencia de unos vínculos y valores sociales superiores a cualquier otro tipo de empresas (Gallardo-Vázquez y Castilla-Polo, 2014). En esa línea Arana (2010) configura a las formas empresariales de ES en la vanguardia de la RSE.

En este contexto, el presente trabajo tiene como objetivo último establecer evidencias empíricas para fundamentar el superior compromiso de las empresas de ES con la RSE en su dimensión interna, a través del análisis concreto del tejido empresarial de la Comunidad Valenciana ( $\mathrm{CV}$, en adelante). Este objetivo se acomete a través de dos objetivos secundarios: en primer término se analizan las prácticas de responsables de la ES de la citada Comunidad, para en segundo lugar, abordar su comparativa con las prácticas de RSE implementadas por el conjunto de empresas valencianas.

Este trabajo se fundamenta en un extenso estudio de campo, realizado a lo largo del año 2015, gracias a la financiación de la Dirección General de Economía Social y Emprendimiento de la Generalitat Valenciana, y cuyo objetivo ha sido analizar el modelo de RSE del tejido productivo de la Comunidad Valenciana.

\section{Revisión de la literatura}

La concepción teórica tradicional de la RSE sitúa su origen en el ámbito del análisis de las relaciones empresa y sociedad en los años setenta (Perdiguero \& García Reche, 2014). El papel de la empresa como una institución económica y social, que no solo debe procurar beneficios, sino que se compromete a insertar sus actividades en el marco del bien común, alcanzó su máxima influencia en los debates públicos desde los años noventa. No obstante, los progresivos desajustes que han venido siendo evidenciados entre los intereses privados de las empresas y el bien común, han consolidado la idea de la necesaria revisión normativa de los propios valores de la economía, que conduzca a la consideración global de las responsabilidades de las empresas, y a la inclusión en su actividad de muchos de los valores de las instituciones públicas (Forética, 2015). En este contexto se inserta el concepto actual de RSE cuyo objetivo es que las empresas sean buenas instituciones y se comporten de manera equilibrada y beneficiosa con la sociedad en su conjunto (Epstein, 2007).

Tras la publicación del Libro Verde, en 2011 la Unión Europea publica la Estrategia Renovada de la Unión Europea sobre Responsabilidad Social de las Empresas, en cuyo contexto se afirma que la RSE permite a las empresas, en colaboración con sus stackeholders, conciliar aspectos económicos, sociales y ambientales (Comisión Europea, 2011). La RSE se despliega a través de una 
dimensión interna ${ }^{3}$, que atiende a los aspectos del compromiso de la empresa con su entorno laboral, con el medioambiente, con sus grupos de interés y con el Buen Gobierno (Curto, 2012; Sajardo (dir), 2009) ${ }^{4}$.

En la ES subyacen unos valores férreamente entroncados con la concepción y los pilares identificativos de la RSE, valores cualitativamente diferentes a los que son propios de la economía dominante, y que revelan una primacía del ser humano y de lo social, sobre el capital. El reto de la ES ha radicado tradicionalmente en cómo traducir esos valores más humanos en principios y en reglas operativas de funcionamiento económico-organizativo. Desde la primera mitad del siglo pasado, los científicos de la ES han tratado de plasmar aquellos valores, en una serie de reglas operativas que fueran consideradas como socialmente deseables, y junto a la democracia, se reseñaron la autoayuda, la autorresponsabilidad, la equidad, la solidaridad, y la vocación social. Tras un periodo experimental, finalmente, consiguieron traducir tales valores en reglas económicas, que fueron denominadas "Principios Cooperativos" (ACI,1995).

Así, la propia naturaleza y principios de actuación de las empresas de ES constituyen la guía y el substrato básico para conformarse como exponentes representativos de una empresa socialmente responsable. Y es que en la Economía Social su funcionamiento y acciones atienden al resultado económico y financiero, puesto que, como cualquier otro modelo de empresa, operan en el mercado, pero éste se halla hábilmente conjugado con el componente social, ambiental y de Buen Gobierno (Sajardo-Moreno y Chaves-Sajardo, 2016).

No obstante es el ámbito de las cooperativas donde los avances institucionales y académicos han sido más numerosos. De la definición de cooperativa de la ACI (2007), y del análisis de las actividades que desarrollan, se infiere una preocupación de las mismas por ofrecer respuestas a necesidades sociales débilmente atendidas (Parlamento Europeo, 2013). Ceballo (2005) realiza una asimilación con los principios cooperativos, y evidencia un claro paralelismo entre los mismos y los principios del Pacto Mundial, matizando que ante la voluntariedad de éstos, los principios Cooperativos constituyen la base de su cultura empresarial, su matriz y el porqué de su existencia.

Adicionalmente Mozas y Poyatos (2010) establecen una relación evidente y estrecha entre los principios de la RSE según la OCDE (2000) y aquellos que forman parte de las cooperativas, mostrando cómo los primeros forman parte de los segundos, configurando ambas tipologías un todo bajo el cual se fundamenta la RSE, y que posiciona a las cooperativas en entidades modelos o exponentes de la misma. Palomo y Valor (2004) afirman que la RSE puede realizarse de forma más efectiva en las cooperativas que en las sociedades capitalistas, puesto que los principios cooperativos que rigen su funcionamiento, recogen de manera clara su compromiso con las prácticas de RSE. Arana (2010) da un paso más al concluir

3 El apartado 2.1 del Libro Verde se aborda específicamente la dimensión interna de la RSI, considerando que: «Las prácticas responsables en lo social afectan en primer lugar a los trabajadores. Abren una vía para administrar el cambio y conciliar el desarrollo social con el aumento de la competitividad».

4 Junto a la dimensión interna de la RSE se halla la dimensión externa que atiende a las relaciones de la empresa con la comunidad, los interlocutores públicos, las ONGs, las entidades de interés social, los consumidores... Y se materializa en el apoyo y/o implicación de la empresa en actividades de contenido social, cultural o deportivo (Sajardo y Serra, 2008). 
que en el concepto de cooperativa queda inherente la RSE, ya que los principios cooperativos la incorporan siendo una forma jurídica estable, fiable y segura en tiempos de crisis, constituyendo un modelo a seguir para lograr la credibilidad del sistema.

Por su parte Vargas (2001) y Vargas y Vaca (2005) conectan cooperativismo y RSE desde la Teoría de los Stakeholders, argumentando que la consecución del equilibrio con los grupos de interés en la empresa puede ser más fácil de conseguir dadas sus peculiaridades en las cooperativas, a saber, su triple condición de socio/consumidor/proveedor, y su fuerte sintonía con los valores sociales de la democracia, igualdad, equidad y solidaridad. Carrasco (2007) plantea que existe un compromiso evidente de las Cooperativas con la comunidad, los trabajadores y el medioambiente. En virtud de lo anterior puede argumentarse que las cooperativas cuentan con un recorrido más amplio en el terreno de la RSE, situándose en una mejor posición estratégica (Collado, 2006).

El citado Libro Verde de la Comisión Europea (2001) ya indicaba que la buena gestión y la RSE es inherente a la dinámica de funcionamiento de las cooperativas, al integrar estructuralmente los intereses de los interlocutores y asumiendo espontáneamente las responsabilidades sociales. La Comunicación de la Comisión Europea (2002) también dejaba claro que la RSE no era un tema novedoso en el ámbito del cooperativismo. Por su lado De Castro (2006) configura a las cooperativas como "modelo de RSE", en base a su naturaleza tendente a desarrollar su actividad de forma responsable, tanto con los socios como con la sociedad, al hilo de unos principios y valores de responsabilidad social que les impelen a la asunción de sus implicaciones a nivel económico, social y ambiental. Belhouari et al. (2005) defienden que la internalización de las cooperativas de la RSE se basa en valores, principios específicos y en su configuración empresarial.

Respecto de los estudios empíricos para valorar la RSE en el ámbito de la ES caben señalar los trabajos de Mozas (1998), y Vargas (2000), los cuales mostraban resultados no excesivamente positivos respecto de la práctica de los principios cooperativos y la RSE. Asimismo es de destacar la investigación de Arcas y Briones (2009) realizada sobre un conjunto de 70 empresas de ES, donde se demuestra que, con independencia de la forma jurídica adoptada (cooperativa o sociedad laboral), estas empresas valoran positivamente (más de 3 puntos sobre 5), todos los ítems de la RSE y los valores de las entidades de la ES, confirmando el cumplimiento por parte de las empresas cooperativas y las sociedades laborales, de los principios de la E $\underline{S}$ y los de la RSE. Asimismo, en las cooperativas se aprecian puntuaciones superiores respecto de las sociedades laborales, tanto respecto de sus valores como de los principios de la RSE, aunque las diferencias entre las puntuaciones medias de las dos variables no eran significativas. En idéntico sentido se sitúan los trabajos de Martín et al. (2007) y Sáez et al. (2003), confirmando que las empresas de Economía Social comparten, en general muchos valores y principios de la RSE, llevándoles a adoptar comportamientos similares.

Díaz y Marcuello (2008) se centran en el reporte de las prácticas de RSE comparando las memorias de empresas de Economía Social que han seguido la guía del GRI, y aquellas que han asumido los principios de la Carta Solidaria, sin resultados concluyentes tras una comparativa. Belhourai et al. (2005) realizan un estudio comparativo de los resultados sociales, ambientales y económicos de un 
conjunto de instituciones financieras cooperativas y no cooperativas recogidos en sus informes de sostenibilidad. Como principal conclusión se constata que no se da una diferencia entre el rendimiento de los bancos comerciales y los cooperativos, aunque si existe una correlación significativa entre la rentabilidad financiera y la socio-ambiental en las instituciones financieras. Modelos de gestión de la RSE en las cooperativas y de Balance social han sido desarrollados por Gallardo-Vázquez y Castilla-Polo (2014) y Mugarra $(2001,2005)$, respectivamente.

Sobre esta base se inserta el presente trabajo que tiene por objeto aportar conocimiento respecto a las prácticas de RSE, en su dimensión interna, de las empresas de ES de la CV. En concreto, se pretenden establecer evidencias empíricas para fundamentar el superior compromiso de las empresas de ES con la RSE interna, valorando su relevancia y extensión a través de la comparativa con las prácticas realizadas por el conjunto de empresas de la CV.

Las hipótesis planteadas y que serán contrastadas en el marco de esta investigación serán:

H1. El superior el compromiso de las empresas de ES en el ámbito laboral, respecto del conjunto de empresa de la $\mathrm{CV}$.

H2. El mayor el compromiso de las empresas de ES con el medio ambiente, en relación al conjunto de empresa de la $\mathrm{CV}$.

H3. El más elevado el compromiso de las empresas de ES con sus grupos de interés, en comparación con el conjunto de empresa de la CV.

H4. El más alto compromiso de las empresas de ES con el Buen Gobierno, tras la comparativa con el total de empresas de la CV.

\section{Metodología del trabajo de campo}

La estrategia metodológica diseñada para el abordaje del presente trabajo ha sido fundamentada en base al conocimiento y análisis del objeto de estudio a través de la perspectiva cuantitativa, la cual se ha ajustado a los objetivos y al contenido de la investigación.

El universo de la investigación lo han conformado las empresas de la CV de los diferentes sectores de actividad y estrato de asalariados. Para ello se ha partido de los datos del Directorio Central de Empresas (DIRCE) (INE, 2015), y se ha determinado una población de 156.034 empresas con más de un empleado.

Para asegurar la óptima realización del trabajo de campo y de obtener una foto fija adecuada a la realidad de las empresas españolas, el muestreo ha sido aleatorio y estratificado en función de las variables área geográfica o provincia y tamaño de empresa según estrato de asalariados.

Con el objetivo de obtener significación estadística pertinente en cada apartado, se ha establecido un criterio de afijación no proporcional a la realidad del tejido económico de la Comunidad. Posteriormente los datos han sido ponderados, devolviendo al conjunto el peso correspondiente a cada variable. La muestra considerada ha sido de 351 empresas. Ello ha permitido hacer estimaciones para el total del universo con un nivel de fiabilidad o margen de error en torno al $\pm 5,2 \%$, un Nivel de Confianza del 95,5\%, 1,96 s respecto de la $\mu$; siendo $\mathrm{p}=\mathrm{q}=0,5$. 
La muestra de empresas de ES considerada ha representado el 5,2\% del total de empresas que conformaron la muestra global, bajo la forma jurídica de cooperativa y sociedad laboral, figuras representativas del sector empresarial o de mercado de la ES (Sajardo, 2012). La distribución ponderada, no ponderada en valores absolutos y en porcentajes se presenta en la tabla siguiente.

Tabla. 1. Distribución de la muestra atendiendo a la forma jurídica.

\begin{tabular}{|c|c|c|c|}
\hline FORMA JURÍDICA & Recuento & Recuento no ponderado & Porcentaje \\
\hline Sdad. Limitada & 288 & 244 & $82,1 \%$ \\
\hline Sdad. Anónima & 40 & 77 & $11,3 \%$ \\
\hline Economía Social & 18 & 23 & $5,2 \%$ \\
\hline Otras & 5 & 7 & $1,4 \%$ \\
\hline TOTALES & 351 & 351 & $100 \%$ \\
\hline
\end{tabular}

Fuente: Elaboración propia.

Las características que han definido la muestra de empresas de ES se presentan en las figuras que siguen:

Gráfico. 1. Distribución de la muestra de empresas de ES por provincias.

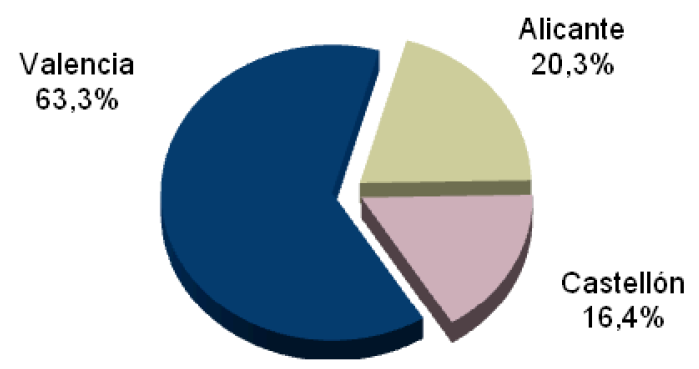

Base: Total muestra de empresas de ES. 
Gráfico. 2. Distribución de la muestra de empresas de ES por sectores de actividad económica.

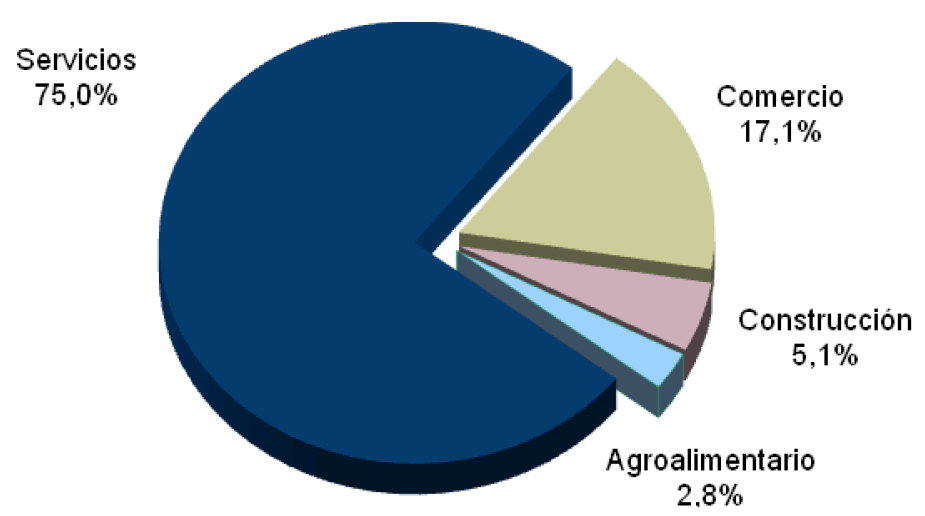

Base: Total muestra de empresas de ES.

Tabla. 2. Distribución de la muestra de empresas de ES por número de trabajadores y antigüedad.

\begin{tabular}{|l|c|c|c|}
\hline EMPLEOS & Más de 50 & Entre $10-50$ & Menor de 10 \\
\hline & $2,4 \%$ & $8,8 \%$ & $88,8 \%$ \\
\hline ANTIGÜEDAD $^{5}$ & Mayor a 25 años & Entre $6-25$ años & Menor a 5 año \\
\hline & $33,6 \%$ & $33,9 \%$ & $18,4 \%$ \\
\hline
\end{tabular}

Fuente: Elaboración propia. Base: Total muestra empresas de ES.

La obtención y procesamiento de información primaria se ha efectuado a través de encuesta telefónica por cuestionario mediante el sistema CATI (Computer Aided Telephone Interview), compuesta por preguntas abiertas y cerradas de unos 10 - 15 minutos de duración. Se han efectuado un total de 9.600 llamadas a teléfonos de línea fija. De éstas, la tasa de contactados fue del 45,4\%, y una duración media de llamada de 14,2 minutos.

El público objetivo de la encuesta han sido los gerentes, responsables o directivos de los departamentos de RRHH, marketing, o en su caso de RSE, de empresas radicadas en la CV. La realización de las entrevistas tuvo lugar del 13 al 21 de noviembre de 2015.

Los métodos de análisis de los datos ha sido, de un lado, la explotación estadística con el programa SPSS basado en la extracción de tablas cruzadas en porcentajes verticales de las preguntas del cuestionario empleado y las variables explicativas o de cabecera identificadas. De otro lado, se han creado nuevas variables a través de condiciones (como la de la clasificación de empresas y su relación con la RSE). Asimismo, se han aplicado los contrastes de contingencia, y

5 Un 3,7\% de empresas de Economía Social que conforman la muestra no concreta su año de constitución. 
en las preguntas numéricas se han obtenido estadísticos como la media y desviación típica.

\section{El compromiso de las empresas valencianas de economía social con su entorno laboral}

Con el objeto de analizar el grado de compromiso de las empresas de ES de la CV con sus trabajadores se consideran cuatro indicadores de comportamiento responsable: 1) la existencia de planes de igualdad; 2) la adopción de medidas de conciliación de la vida familiar y laboral; 3) la participación de los trabajadores en planes de formación continua, y 4) la integración en la plantilla de personas pertenecientes a colectivos desfavorecidos.

\subsection{Planes de Igualdad}

Sólo un 9,2 \% del total de empresas de la CV tiene implantado un Plan de Igualdad que garantice la igualdad de oportunidades entre hombres y mujeres en la estructura organizativa de la empresa. Este nivel se eleva al 16,5\% en el caso de las empresas de ES. Esta incidencia es mayor en el sector agroalimentario en el 21,3\% de las mismas, el industrial, con un 19,9\%, y el del comercio (un 18,4\%), frente al $2,7 \%$ de empresas constructoras.

Asimismo se constata una relación positiva entre mayor tamaño de las empresas con superiores porcentajes de Planes de Igualdad (PI), a tenor de la normativa legal de obligado cumplimiento para las empresas más grandes. Así, las empresas de más de 50 trabajadores disponen en mayor proporción (32,3\%) de esta herramienta, seguidos por las empresas de tamaño medio (de 10 a 50 trabajadores) con un $21,9 \%$ y finalmente las de menos de 10 trabajadores con un 7,8\% del total de empresas consultadas.

Tabla.3. Incidencia de los PI en las Empresas Valencianas por características de las mismas

EMPRESAS QUE CUENTAN CON UN PLAN DE IGUALDAD

\begin{tabular}{|c|l|c|}
\hline \multirow{3}{*}{$\begin{array}{c}\text { SEGÚN NÚMERO DE } \\
\text { TRABAJADORES }\end{array}$} & Hasta 10 trabajadores & $7,8 \%$ \\
\cline { 2 - 3 } & De 10 a 50 trabajadores & $21,9 \%$ \\
\cline { 2 - 3 } & Más de 50 trabajadores & $32,3 \%$ \\
\hline \multirow{3}{*}{ FORMA JURIDICA } & Sociedad Limitada & $8,1 \%$ \\
\hline & Sociedad Anónima & $14,6 \%$ \\
\cline { 2 - 3 } & Empresas de Economía social & $16,5 \%$ \\
\hline & Otras & $1,5 \%$ \\
\hline \multirow{2}{*}{ SECTOR } & Agroalimentario & $21,3 \%$ \\
\hline & Industrial & $19,9 \%$ \\
\hline & Construcción & $2,7 \%$ \\
\hline & Comercio & $18,4 \%$ \\
\hline & Servicios & $5,8 \%$ \\
\hline
\end{tabular}

Base: Total de empresas. 
Se trata de PI implantados en el 84,2\% de las empresas de manera voluntaria, es decir, más allá de su obligación legal para empresas de mayor tamaño, siendo por tanto una clara evidencia de actitud proactiva de RSE por parte del tejido empresarial valenciano. Ello es especialmente evidente en el caso de las microempresas, donde el 85,9\% de las mismas cuentan con uno. En tan sólo el $11,2 \%$ de las empresas valencianas que cuentan con PI existen mecanismos de control, que son de naturaleza interna en el 10,7\% de aquellas.

En las plantillas de las empresas de la CV que dicen tener un Plan de igualdad, se observa un peso del colectivo femenino del 49,2\%. Este porcentaje se eleva al $71,2 \%$ en el ámbito de las empresas de ES de la citada Comunidad, destacando sobre manera, frente al $37,2 \%$ de mujeres en estas empresas a nivel nacional. La presencia femenina es mayor en el sector servicios $(52,3 \%)$ e industrial $(51,7 \%)$, revelando una clara segregación horizontal, que replica el panorama nacional, $\mathrm{y}$ entre las empresas de más de 50 trabajadores, donde el 54,1\% de sus trabajadores son mujeres. La media de mujeres directivas en las empresas valencianas con PI es el 27,7\%, clara constatación del denominado "Techo de Cristal", rompiéndose claramente el mismo en el ámbito de las empresas de Economía Social, donde este nivel se eleva al $55,5 \%$.

\subsection{Medidas de conciliación vida familiar y vida laboral}

Respecto a las medidas de conciliación de la vida familiar y laboral, más allá de las establecidas legalmente, el 22,7\% de empresas de la CV afirma tenerlas. Este nivel se eleva en más de seis puntos en el ámbito de las empresas de ES, alcanzando el $28,9 \%$. Estas acciones tienen una mayor incidencia en las empresas de mayor tamaño, en el $42,1 \%$ de las mismas, en las que trabajan en el sector de la construcción $(30,0 \%)$ y del comercio $(24,2 \%)$.

Tabla. 4. Incidencia de las medidas de conciliación de la vida familiar y laboral en las Empresas de la CV por características de las mismas.

PERFIL DE EMPRESAS CON MEDIDAS DE CONCILIACIÓN DE VIDA FAMILIAR Y LABORAL

\begin{tabular}{|c|c|c|}
\hline \multirow{3}{*}{$\begin{array}{l}\text { SEGÜN NÜMERO DE } \\
\text { TRABAJADORES }\end{array}$} & Hasta 10 trabajadores & $22,4 \%$ \\
\hline & De 10 a 50 trabajadores & $22,6 \%$ \\
\hline & Más de 50 trabajadores & $42,1 \%$ \\
\hline \multirow{4}{*}{ FORMA JURÍDICA } & Sociedad Limitada & $21,9 \%$ \\
\hline & Sociedad Anónima & $28,6 \%$ \\
\hline & Empresas de Economía social & $28,9 \%$ \\
\hline & Otras & $1,5 \%$ \\
\hline \multirow{5}{*}{ SECTOR } & Agroalimentario & $22,5 \%$ \\
\hline & Industrial & $22,6 \%$ \\
\hline & Construcción & $30,0 \%$ \\
\hline & Comercio & $24,2 \%$ \\
\hline & Servicios & $21,4 \%$ \\
\hline
\end{tabular}

Fuente: Total de las empresas. 
El tipo y significación de medidas de conciliación implementadas por las empresas de la CV se halla en el siguiente gráfico 3.

Gráfico. 3. Incidencia de medidas de conciliación de la vida laboral y familiar en las empresas valencianas socialmente responsables (EVSR).

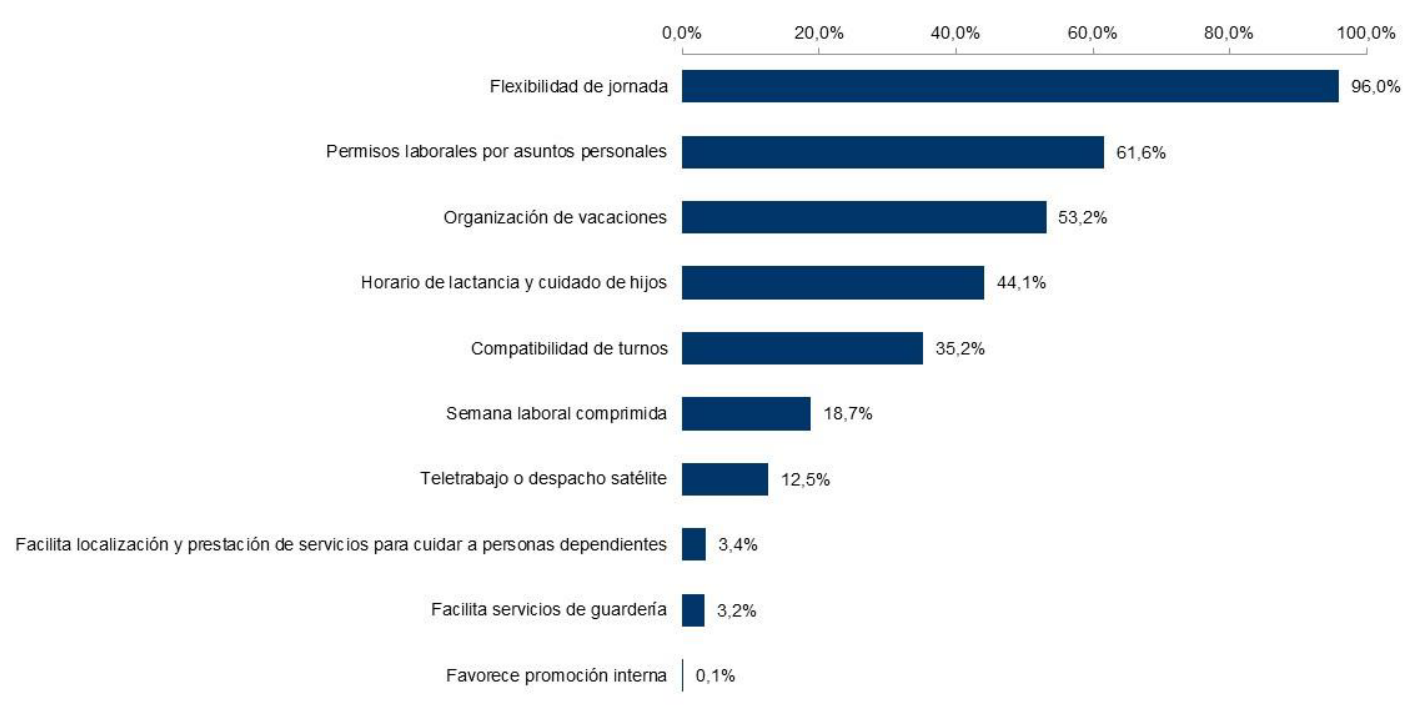

Base: Empresas valencianas que señalan disponer de medidas de conciliación de vida familiar y laboral.

\subsection{Planes de formación continua}

Un 47,4\% de las empresas de la CV ha realizado programas de formación continua durante los últimos tres años para sus trabajadores. Este nivel es superado ampliamente por las empresas de ES, entre las cuales el 61,8\% había implementado programas formativos para sus trabajadores. La media de trabajadores que han participado en tales programas era del 52,2\% para el total de empresas de la Comunidad, reduciéndose ligeramente al 51,8\% para el caso de las empresas de ES. 
Tabla. 5. Incidencia de la formación continua en las Empresas de la CV según características de las mismas.

\begin{tabular}{|c|c|c|}
\hline \multicolumn{3}{|c|}{$\begin{array}{c}\text { EMPRESAS QUE HAN PARTICIPADO EN FORMACIÓN } \\
\text { CONTINUA }\end{array}$} \\
\hline \multirow{3}{*}{$\begin{array}{l}\text { SEGÚN NÚMERO DE } \\
\text { TRABAJADORES }\end{array}$} & Hasta 10 trabajadores & $45,3 \%$ \\
\hline & De 10 a 50 trabajadores & $66,2 \%$ \\
\hline & Más de 50 trabajadores & $89,0 \%$ \\
\hline \multirow{4}{*}{ FORMA JURIDICA } & Sociedad Limitada & $48,0 \%$ \\
\hline & Sociedad Anónima & $42,0 \%$ \\
\hline & Empresas de Economía social & $61,8 \%$ \\
\hline & Otras & $6,2 \%$ \\
\hline \multirow{5}{*}{ SECTOR } & Agroalimentario & $93,1 \%$ \\
\hline & Industrial & $60,3 \%$ \\
\hline & Construcción & $38,2 \%$ \\
\hline & Comercio & $43,1 \%$ \\
\hline & Servicios & $46,1 \%$ \\
\hline
\end{tabular}

Base: Total de empresas

Se trata de programas que benefician, en el $99,1 \%$ de los casos, al colectivo genérico de trabajadores sin diferenciación por sexo, estando dirigidos prioritariamente a los operarios y al personal de administración y servicios, y en menor medida a los directivos.

\subsection{Inserción socio-laboral de colectivos desfavorecidos}

Del total de empresas que conforman el tejido productivo de la CV, el 10,8\% tienen incorporados en sus plantillas trabajadores con especiales dificultades de empleo. Este nivel se reduce al 7,0\% en el caso de las empresas de ES. Esta medida de responsabilidad social es especialmente relevante en las empresas de más de $5^{\circ}$ trabajadores $(62,8 \%)$, en el sector agroalimentario $(18,6 \%)$ e industrial $(17,6 \%)$.

Tabla. 6. Incidencia de la integración socio-laboral de colectivos desfavorecidos en las EVSR por características de las mismas.

\section{EMPRESAS QUE INCORPORAN COLECTIVOS LABORALMENTE DESFAVORECIDOS EN LA PLANTILLA}

\begin{tabular}{|c|l|c|}
\hline \multirow{3}{*}{$\begin{array}{c}\text { SEGUN NEUMERO DE } \\
\text { TRABAJADORES }\end{array}$} & Hasta 10 trabajadores & $\mathbf{8 , 9 \%}$ \\
\cline { 2 - 3 } & De 10 a 50 trabajadores & $23,8 \%$ \\
\hline \multirow{3}{*}{ FORMA JURIDICA } & Más de 50 trabajadores & $62,8 \%$ \\
\hline & Sociedad Limitada & $11,0 \%$ \\
\hline & Sociedad Anónima & $11,3 \%$ \\
\hline & Empresas de Economia social & $7.0 \%$ \\
\hline & Otras & $4,7 \%$ \\
\hline \multirow{3}{*}{ SECTOR } & Agroalimentario & $18,6 \%$ \\
\hline & Industrial & $17,6 \%$ \\
\hline & Construcción & $0,3 \%$ \\
\hline & Comercio & $\mathbf{8 , 6 \%}$ \\
\hline & Servicios & $11,6 \%$ \\
\hline
\end{tabular}

Base: Total de empresas 
La incidencia de inserción por tipo de colectivo desfavorecido se observa en el gráfico 2 .

Gráfico. 4. Nivel de incidencia por tipo de colectivo desfavorecido integrados en las EVSR.

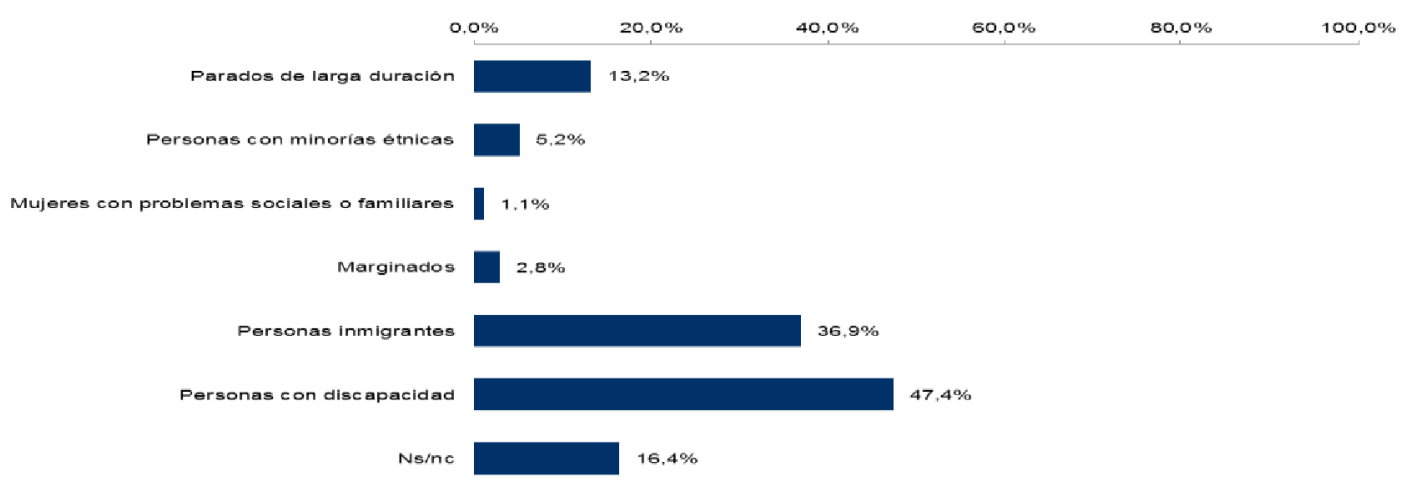

Base: empresas que tienen en sus plantillas trabajadores de colectivos desfavorecidos.

El gráfico que sigue muestra el impacto de las responsabilidades laborales de las empresas de ES respecto del total de empresas de la CV. Como puede constatarse el compromiso laboral de la ES valenciana es superior al del conjunto de empresas de la Comunidad, salvo respecto de la inserción de trabajadores con especiales dificultades de empleo, donde se da una diferencia de algo más de tres puntos porcentuales, en contra de la ES. Las acciones de RSE en el terreno laboral de mayor significación son la existencia de planes de formación continua para sus trabajadores y las medidas de conciliación de la vida familiar y laboral. En menor medida los planes de igualdad de carácter voluntario. 
Gráfico. 5. Impacto de las responsabilidades laborales de la ES respecto total de empresas de la CV.

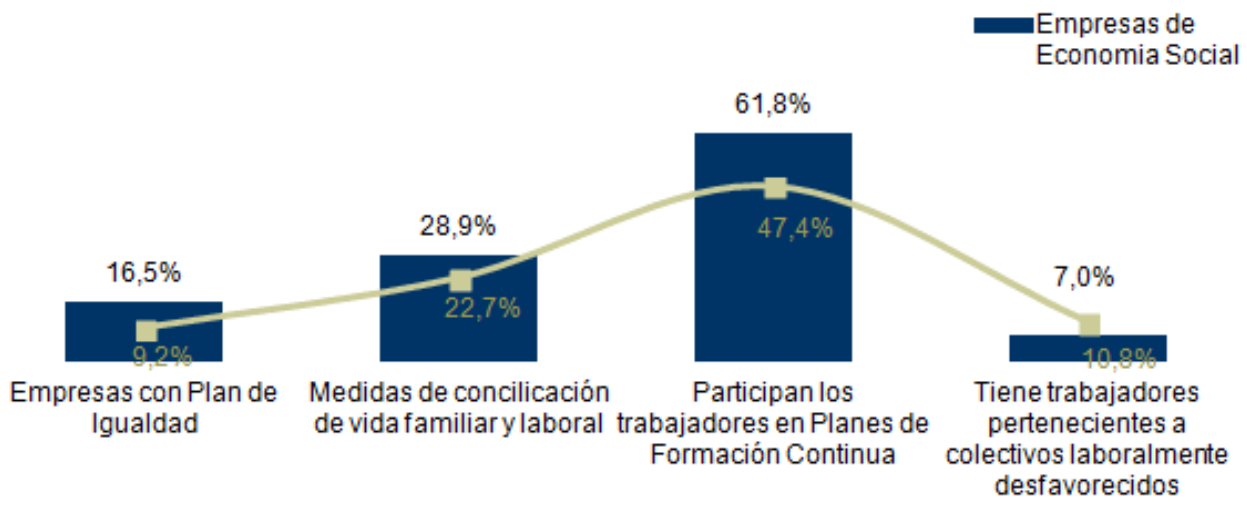

Fuente: Elaboración propia

Tras los resultados evidenciados la $\mathrm{H} 1$ relativa al mayor compromiso de las empresas de ES de la CV en el ámbito laboral, es aceptada, salvo en el ítem "inserción socio-laboral de colectivos desfavorecidos", con un diferencial negativo para la ES superior a 3 puntos porcentuales.

\section{El compromiso de las empresas valencianas de economía social con el medio ambiente}

Dos son los ámbitos que fueron explorados para valorar el compromiso ambiental de las empresas valencianas con el medioambiente: por un lado, la ecología organizacional interna (nivel de calidad ambiental y eliminación de barreras arquitectónicas); por otro lado, las medidas ambientales externas (reciclado de residuos, uso energía limpia...).

\subsection{Ecología organizacional interna}

\subsubsection{Medidas de calidad ambiental}

El 56,6\% en las empresas de ES de la CV disponen de medidas de calidad ambiental Este nivel que se reduce al $43,2 \%$ para el conjunto de las empresas de la Comunidad. La incidencia de estas medias es especialmente relevante entre las empresas de más de 50 trabajadores $(79,0 \%)$, y del sector industrial $(88,0 \%)$. 
Tabla. 7. Desglose de empresas de la CV que disponen de medidas internas de calidad medioambiental.

\begin{tabular}{|l|l|l|}
\hline \multirow{2}{*}{$\begin{array}{l}\text { SEGÚN NÚMERO } \\
\text { TRABAJADORES }\end{array}$} & $\begin{array}{l}\text { DE } \\
\text { Hasta } 10 \text { trabajadores }\end{array}$ & $41,5 \%$ \\
\hline \multirow{3}{*}{ FORMA JURÍDICA } & De 10 a 50 trabajadores & $57,2 \%$ \\
\hline & Más de 50 trabajadores & $79,0 \%$ \\
\hline \multirow{3}{*}{ SECTOR } & Sociedad Limitada & $42,8 \%$ \\
\hline & Sociedad Anónima & $36,2 \%$ \\
\hline & Empresas de Economía social & $56,6 \%$ \\
\hline & Otras & $73,9 \%$ \\
\hline & Agroalimentario & $32,8 \%$ \\
\hline & Industrial & $88,0 \%$ \\
\hline & Construcción & $12,8 \%$ \\
\hline & Comercio & $41,1 \%$ \\
\hline & Servicios & $43,3 \%$ \\
\hline
\end{tabular}

Base: Total de empresas.

\subsubsection{Eliminación de barreras arquitectónicas}

En el ámbito de este trabajo se ha realizado un análisis especial en el tema de la eliminación de las barreras arquitectónicas, punto éste de crucial incidencia dentro de las responsabilidad social interna, dado que además de formar parte de la calidad medioambiental, mejora las relaciones laborales de aquéllos colectivos de empleados que tengan o puedan tener algún tipo de minusválida, demostrando el interés de la empresa por adaptarse a posibles contingencias futuras que puedan resultar negativas para sus empleados. Entre las empresas de ES el uso de medidas de adecuación al entorno laboral (eliminación de barreras arquitectónicas) es muy reducida, existiendo en tan sólo el $4,6 \%$ de las mismas. Este nivel se eleva al 25,2\% si se considera el total de empresas de la Comunidad siendo su incidencia superior en las empresas más grandes $(63,0 \%)$, aunque el nivel de las microempresas es superior a la media $(24,3 \%)$, y en aquellas que se hallan en el sector agroalimentario $(48,1 \%)$ y servicios $(30,2 \%)$.

Tabla. 8. Empresas de la CV que disponen de medidas de adecuación al entorno laboral.

\begin{tabular}{|c|c|c|}
\hline \multirow{3}{*}{$\begin{array}{l}\text { SEGÚN NÚMERO DE } \\
\text { TRABAJADORES }\end{array}$} & Hasta 10 trabajadores & $24,3 \%$ \\
\hline & De 10 a 50 trabajadores & $29,9 \%$ \\
\hline & Más de 50 trabajadores & $63,0 \%$ \\
\hline \multirow{4}{*}{ FORMA JURÍDICA } & Sociedad Limitada & $27,5 \%$ \\
\hline & Sociedad Anónima & $20,9 \%$ \\
\hline & Empresas de Economía social & $4,6 \%$ \\
\hline & Otras & $4,7 \%$ \\
\hline
\end{tabular}




\begin{tabular}{|l|l|l|}
\hline \multirow{4}{*}{ SECTOR } & Agroalimentario & $48,1 \%$ \\
\cline { 2 - 3 } & Industrial & $7,6 \%$ \\
\cline { 2 - 3 } & Construcción & $12,4 \%$ \\
\cline { 2 - 3 } & Comercio & $16,8 \%$ \\
\cline { 2 - 3 } & Servicios & $30,2 \%$ \\
\hline
\end{tabular}

Base: Total de empresas.

\subsection{Prácticas medioambientales externas}

Para el análisis del compromiso medioambiental externo de las empresas de ES de la CV se han tenido en cuenta varias áreas:

\subsubsection{Reciclado de residuos}

La práctica totalidad de las empresas de ES de la CV, el 92,7\%, reciclan los residuos objeto de su actividad. Este nivel desciende al 72,8\% para el total de empresas de la Comunidad. El reciclado de residuos es superior a la media entre las grandes empresas $(88,0 \%)$, y en los sectores agroalimentario $(93,6 \%)$ e industrial $(90,2 \%)$.

Tabla. 9. Incidencia del reciclado de residuos en las empresas de la CV por características de las mismas.

\begin{tabular}{|c|c|c|}
\hline \multirow{3}{*}{$\begin{array}{l}\text { SEGÚN NÚMERO DE } \\
\text { TRABAJADORES }\end{array}$} & Hasta 10 trabajadores & $72,2 \%$ \\
\hline & De 10 a 50 trabajadores & $77,5 \%$ \\
\hline & Más de 50 trabajadores & $88,0 \%$ \\
\hline \multirow{4}{*}{ FORMA JURÍDICA } & Sociedad Limitada & $72,8 \%$ \\
\hline & Sociedad Anónima & $63,5 \%$ \\
\hline & Empresas de Economía social & $92,7 \%$ \\
\hline & Otras & $76,9 \%$ \\
\hline \multirow{5}{*}{ SECTOR } & Agroalimentario & $93,6 \%$ \\
\hline & Industrial & $90,2 \%$ \\
\hline & Construcción & $60,9 \%$ \\
\hline & Comercio & $69,4 \%$ \\
\hline & Servicios & $72,3 \%$ \\
\hline
\end{tabular}

Base: Total de empresas.

\subsubsection{Control de emisiones atmosféricas y vertidos}

El 16,1\% entre las empresas de ES controlan sus emisiones a la atmósfera y los vertidos objeto de su actividad. Este nivel se reduce a un exiguo 9,7\% para el total de empresas valencianas. De nuevo son las empresas de más de 50 trabajadores las 
que más controlan las emisiones a la atmósfera y los vertidos $(40,3 \%)$, y las de los sectores agroalimentario $(31,6 \%)$ e industrial $(33,2 \%)$.

Tabla. 10. Empresas de la CV que disponen de control de emisiones atmosféricas o vertidos.

\begin{tabular}{|c|c|c|}
\hline \multirow{3}{*}{$\begin{array}{l}\text { SEGÚN NÚMERO DE } \\
\text { TRABAJADORES }\end{array}$} & Hasta 10 trabajadores & $8,6 \%$ \\
\hline & De 10 a 50 trabajadores & $17,8 \%$ \\
\hline & Más de 50 trabajadores & $40,3 \%$ \\
\hline \multirow{4}{*}{ FORMA JURÍDICA } & Sociedad Limitada & $8,8 \%$ \\
\hline & Sociedad Anónima & $14,7 \%$ \\
\hline & Empresas de Economía social & $16,1 \%$ \\
\hline & Otras & --- \\
\hline \multirow{5}{*}{ SECTOR } & Agroalimentario & $31,6 \%$ \\
\hline & Industrial & $33,2 \%$ \\
\hline & Construcción & $11,9 \%$ \\
\hline & Comercio & $1,1 \%$ \\
\hline & Servicios & $7,9 \%$ \\
\hline
\end{tabular}

Base: Total de empresas.

\subsubsection{Uso de energía limpia o renovable}

El 15,6\% de las empresas valencianas de ES utilizan energía limpia, nivel superior al $11,7 \%$ relativo al total de empresas de la Comunidad. Es entre las empresas más grandes y en los sectores agroalimentario e industrial donde mayor incidencia posee esta medida, con niveles respectivos del 40,3\%, 31,3\% y 20,3\%, respectivamente.

Tabla. 11. Empresas de la CV que usan energías limpias o renovables.

\begin{tabular}{|c|c|c|}
\hline \multirow{3}{*}{$\begin{array}{l}\text { SEGÚN NÚMERO DE } \\
\text { TRABAJADORES }\end{array}$} & Hasta 10 trabajadores & $10,1 \%$ \\
\hline & De 10 a 50 trabajadores & $26,2 \%$ \\
\hline & Más de 50 trabajadores & $40,3 \%$ \\
\hline \multirow{4}{*}{ FORMA JURÍDICA } & Sociedad Limitada & $10,4 \%$ \\
\hline & Sociedad Anónima & $20,6 \%$ \\
\hline & Empresas de Economía social & $15,6 \%$ \\
\hline & Otras & --- \\
\hline \multirow{3}{*}{ SECTOR } & Agroalimentario & $31,3 \%$ \\
\hline & Industrial & $20,3 \%$ \\
\hline & Construcción & $12,2 \%$ \\
\hline
\end{tabular}




\begin{tabular}{|l|l|}
\hline Comercio & $22,4 \%$ \\
\hline Servicios & $6,8 \%$ \\
\hline
\end{tabular}

Base: Total de empresas.

\subsubsection{Reutilización de envases o embalajes}

El 33,8\% de las empresas de ES de la CV reciclan envases y embalajes, nivel inferior al 48,4\% del total de empresas de la Comunidad. Aunque son las empresas grandes las que más reutilizan envases y embalajes, muy por encima de la media $(70,2 \%)$, su incidencia es especialmente significativa entre los sectores industrial $(79,5 \%)$ y de comercio $(62,4 \%)$.

Tabla. 12. Empresas de la CV que reutilizan materiales.

\begin{tabular}{|c|c|c|}
\hline \multirow{3}{*}{$\begin{array}{l}\text { SEGÚN NÚMERO DE } \\
\text { TRABAJADORES }\end{array}$} & Hasta 10 trabajadores & $47,6 \%$ \\
\hline & De 10 a 50 trabajadores & $54,4 \%$ \\
\hline & Más de 50 trabajadores & $70,2 \%$ \\
\hline \multirow{4}{*}{ FORMA JURÍDICA } & Sociedad Limitada & $49,3 \%$ \\
\hline & Sociedad Anónima & $52,0 \%$ \\
\hline & Empresas de Economía social & $33,8 \%$ \\
\hline & Otras & $23,1 \%$ \\
\hline \multirow{5}{*}{ SECTOR } & Agroalimentario & $55,0 \%$ \\
\hline & Industrial & $79,5 \%$ \\
\hline & Construcción & $37,1 \%$ \\
\hline & Comercio & $62,4 \%$ \\
\hline & Servicios & $42,3 \%$ \\
\hline
\end{tabular}

Base: Total de empresas.

Frente al reducido 9,3\% del total de empresas de la Comunidad, un significativo $19,1 \%$ de empresas de la ES valenciana reconoce disponer de certificaciones ambientales. Resultado superior que para el resto de formas jurídicas, tanto para las sociedades anónimas como para las sociedades limitadas, que disponen de las mismas en un $9,8 \%$ y $8,7 \%$ de los casos, respectivamente. Son significativas a este nivel las empresas del sector industrial $(23,3 \%)$ y agroalimentario $(20,3 \%)$. Sin embargo en el seguimiento de protocolos ambientales de carácter internacional, se constata un exiguo $0,2 \%$ de empresas de ES que los siguen, que llega a un reducido $1,6 \%$ para el total de empresas valencianas, especialmente de más de 50 trabajadores $(7,5 \%)$, y del sector agroalimentario $(9,3 \%)$. 
Gráfico. 6. Impacto de las responsabilidades ambientales de la Economía Social respecto total de empresas de la CV.

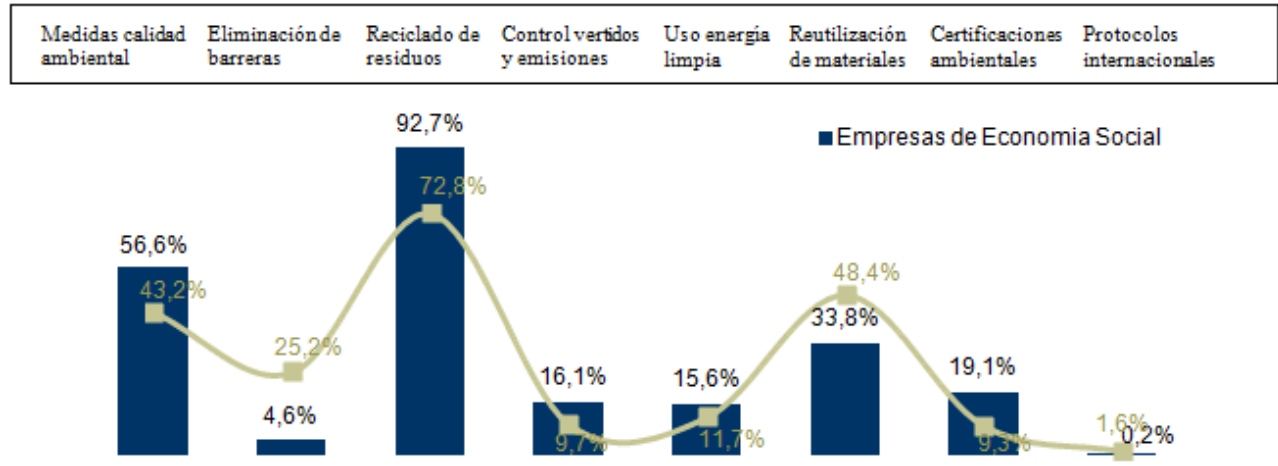

Fuente: Elaboración propia.

La comparativa sobre las responsabilidades ambientales de las empresas de ES en relación al total de las empresas de la Comunidad, constata un significativo compromiso en el reciclado de residuos (superior en más de 20 puntos porcentuales), y en la utilización de medidas de calidad ambiental (mayor en más de 10 puntos porcentuales). En el control de las emisiones a la atmósfera y vertidos a la biosfera, la ES valenciana se halla comprometida en un nivel superior en más de 6 puntos porcentuales que el resto de empresas, y en poco más de 4 puntos porcentuales respecto del uso de energía limpia y renovable.

Sin embargo existen medidas de responsabilidad ambiental donde las empresas de ES se hallan inferiormente comprometidas, como es el caso de la reutilización de materiales, pero especialmente respecto de aquellas relativas a la adecuación al entorno laboral, como la eliminación de barreras arquitectónicas principalmente, donde la diferencia en contra de la ES es más que notable (mayor de 15 puntos porcentuales).

Es de remarcar adicionalmente que las empresas de ES cuentan con certificaciones ambientales en mayor y significativa medida que el conjunto de empresas de la Comunidad (un 19,1\% de empresas de ES, frente al 9,3\% para el total de empresas). No obstante, sólo muy marginalmente cumplen protocolos internacionales de carácter medioambiental, en el $0,2 \%$ de los casos.

Por lo tanto la $\mathrm{H} 2$ es aceptada sólo parcialmente con las matizaciones efectuadas.

\section{El compromiso de las empresas valencianas de economía social con sus grupos de interés}

El compromiso responsable de las empresas de la CV con sus grupos de interés (Stakeholders), se valora en qué medida la empresa valenciana produce, invierte y atiende a sus demandantes ética y responsablemente. En este contexto se aborda el 
análisis de los procesos de control sobre las actividades de sus proveedores o suministradores, en términos de respeto de la jornada y horarios laborales, derechos humanos, condiciones contractuales, legislación local vigente, calidad de los productos y factores suministrados, respeto al medioambiente, no utilización del trabajo infantil, reinversión de beneficios a nivel local, o de prácticas de comercio justo.

En segundo término se estudia, el compromiso o responsabilidad de las empresas de la CV respecto de los consumidores, que se basa en el establecimiento de medidas informativas y de atención a los mismos, tanto respecto del producto o servicio suministrado, como sobre los procedimientos y cauces adecuados para la resolución de conflictos. $\mathrm{Y}$ por último se analiza la Inversión Socialmente Responsable (ISR), como aquella que combina los objetivos de rentabilidad financiera de los inversores con sus preocupaciones sociales, éticas y medioambientales.

\subsection{El control sobre la cadena de proveedores-suministradores}

El control de las empresas de ES de la CV sobre su cadena de proveedores y suministradores es una medida de RSE que tiene escasa presencia, dado que sólo el $8,8 \%$ de las mismas reconoce haber llevado a cabo algún tipo de medida. Este control es seguido superiormente por el conjunto de empresas de la Comunidad, donde el 13,2\% de las mismas lo implementa.

Entre las empresas de mayor tamaño el control de la cadena de proveedoressuministradores tiene una especial incidencia, dándose en el 60,9\% de las mismas. También es de destacar su seguimiento en el sector industrial $(28,1 \%)$ y agroalimentario $(15,8 \%)$.

Tabla. 13. Incidencia en el control de la cadena de proveedores/suministradores por las EVSR.

\begin{tabular}{|c|c|c|c|}
\hline \multirow{3}{*}{$\begin{array}{l}\text { SEGÚN NÚMERO } \\
\text { TRABAJADORES }\end{array}$} & \multirow{3}{*}{$\mathrm{DE}$} & Hasta 10 trabajadores & $11,3 \%$ \\
\hline & & De 10 a 50 trabajadores & $27,7 \%$ \\
\hline & & Más de 50 trabajadores & $60,9 \%$ \\
\hline \multirow{4}{*}{ FORMA JURÍDICA } & & Sociedad Limitada & $14,1 \%$ \\
\hline & & Sociedad Anónima & $9,9 \%$ \\
\hline & & Empresas de Economía social & $8,8 \%$ \\
\hline & & Otras & $4,7 \%$ \\
\hline \multirow{5}{*}{ SECTOR } & & Agroalimentario & $18,5 \%$ \\
\hline & & Industrial & $28,1 \%$ \\
\hline & & Construcción & $5,3 \%$ \\
\hline & & Comercio & $12,4 \%$ \\
\hline & & Servicios & $12,5 \%$ \\
\hline
\end{tabular}

Base: Total de empresas. 
Respecto del tipo de medidas implementadas destacan por su incidencia las relativas al respeto por el medioambiente $(55,9 \%)$, el cumplimiento de la legislación vigente, en un $55,3 \%$, el respeto a las condiciones contractuales (54,3\%), y el control de calidad de los productos suministrados $(53,8 \%)$. A gran distancia se encuentra el respeto a los derechos humanos, realizado en el $39,1 \%$ de las empresas de la Comunidad, y la práctica del comercio justo en un 34,3\% de las mismas. Por último son medidas también implementadas por las empresas valencianas el control del trabajo forzado, en un $32,4 \%$, y la no utilización de trabajo infantil $(25,5 \%)$. Por su débil incidencia respecto del resto de medidas, se encuentran en una posición preeminente entre los factores a controlar en la relación con sus proveedores y suministradores.

Gráfico. 7. Tipos de medidas de control a sus proveedores y suministradores implementadas por las EVSR.

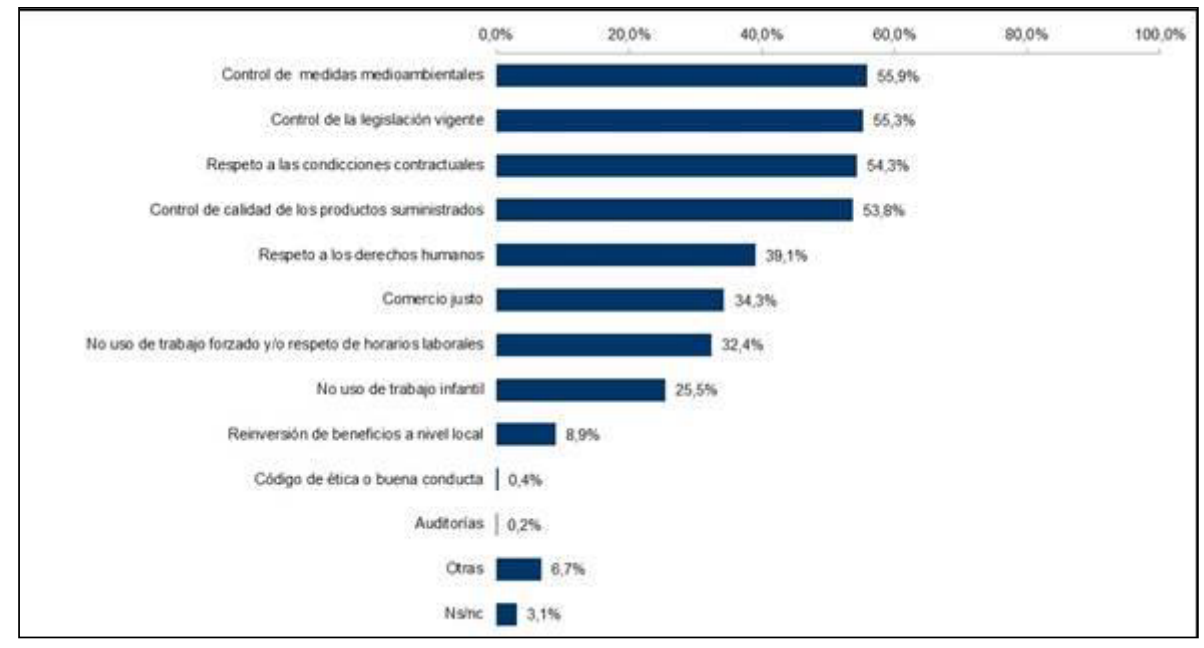

Base: empresas valencianas que señalan realizar controles a sus proveedores.

\subsection{Las medidas de información al consumidor}

En el ámbito de las medidas de información al consumidor las empresas valencianas de ES se hallan ligeramente más comprometidas que en las precedentes, dado que un $28,4 \%$ declaran haberlas desplegado con una antigüedad mínima de tres años. Este tipo de medidas es seguida más débilmente si se considera el conjunto de empresas de la CV, con una incidencia del 21,5\%. Destacan en este sentido las grandes empresas, dándose en el 38,1\% de las mismas. Por sectores de actividad la incidencia es mayor en el sector agroalimentario (en el $23,9 \%$ ) y en el de servicios $(22,4 \%)$, pero en cualquier caso con niveles inferiores al evidenciado para el conjunto de empresas de la ES. 
Tabla. 14. Empresas de la CV que disponen de medidas de responsabilidad social hacia el consumidor por características de las mismas

\begin{tabular}{|c|c|c|}
\hline \multirow{3}{*}{$\begin{array}{l}\text { SEGÚN NÚMERO DE } \\
\text { TRABAJADORES }\end{array}$} & Hasta 10 trabajadores & $21,5 \%$ \\
\hline & De 10 a 50 trabajadores & $18,7 \%$ \\
\hline & Más de 50 trabajadores & $38,1 \%$ \\
\hline \multirow{4}{*}{ FORMA JURÍDICA } & Sociedad Limitada & $21,3 \%$ \\
\hline & Sociedad Anónima & $19,4 \%$ \\
\hline & Empresas de Economía social & $28,4 \%$ \\
\hline & Otras & $24,6 \%$ \\
\hline \multirow{5}{*}{ SECTOR } & Agroalimentario & $23,9 \%$ \\
\hline & Industrial & $16,1 \%$ \\
\hline & Construcción & $19,4 \%$ \\
\hline & Comercio & $21,4 \%$ \\
\hline & Servicios & $22,4 \%$ \\
\hline
\end{tabular}

Base: Total de empresas.

El estudio sobre el tipo de medias de información al consumidor desarrolladas por las empresas de la ES en la CV en primer término destacan aquellas relativas a la información sobre el cumplimiento de la normativa legal que obliga a sus productos, en el 77,7\% de empresas; la existencia de protocolos para la resolución de conflictos con el consumidor, en un $69,2 \%$, y la información de la calidad del producto suministrado al consumidor, en un $68,7 \%$ de empresas. En un segundo bloque se hallan las actividades de información sobre la calidad de los factores empleados para su elaboración, que se dan en el $50 \%$ de empresas. Las certificaciones sobre el consumidor aparecen en el $42 \%$ de las mismas. Un 39,5\% de empresas valencianas dispone de informes sobre medidas correctas de consumo y riesgo, y finalmente con un porcentaje muy bajo, solo el 1,2\% de empresas de la Comunidad dispone de fichas de seguridad en el consumo de sus outputs. 
Gráfico. 8. Medidas de información al consumidor desplegadas por las EVSR.

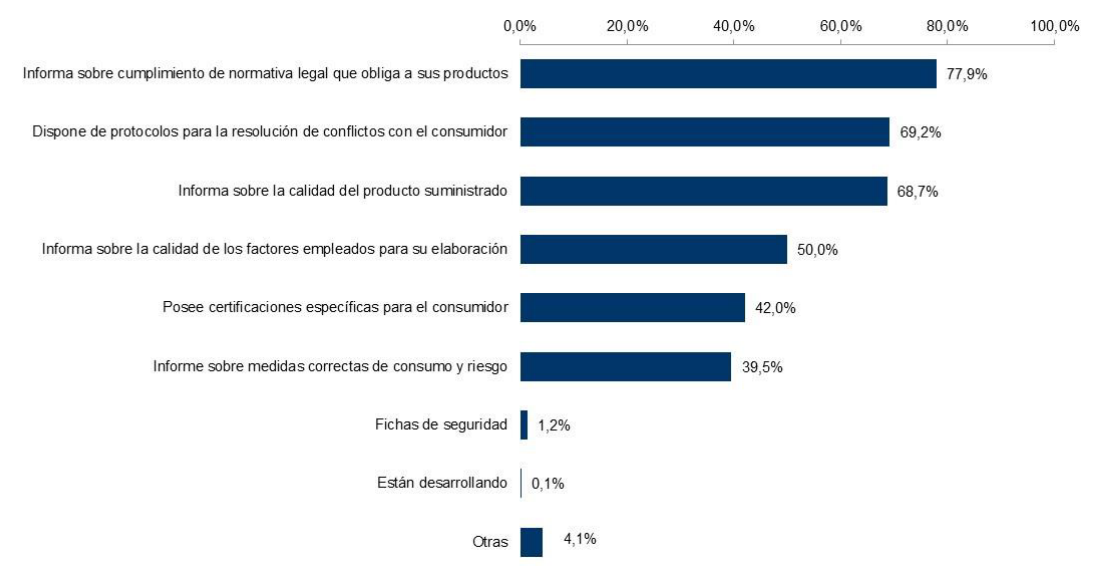

Base: empresas que dicen reconocen poseer medidas de información al consumidor.

\subsection{La Inversión Socialmente Responsable (ISR)}

Aunque el concepto de ISR responsable es un fenómeno incipiente para las empresas de la CV, dado que sólo un $5,4 \%$ de las mismas las realiza, resulta claramente significativo que en el caso de las empresas de ES esta práctica responsable se halle extendida en el $14,4 \%$ de las mismas. Ambos porcentajes resultan muy alejados del $34 \%$ de grandes empresas españolas que realizaban ISR en $2013^{6}$. Se trata de una práctica de mayor consideración en las empresas más grandes $(19,0 \%)$, destacando los sectores agroalimentario y de servicios, con niveles de incidencia respectiva del $8,5 \%$ y $6,1 \%$, en todo caso alejados del peso hallado en la Economía Social.

Tabla. 15. Incidencia de las Inversiones Socialmente Responsables por características de las EVSR.

\begin{tabular}{|c|c|c|}
\hline \multirow{3}{*}{$\begin{array}{l}\text { SEGÚN NÚMERO DE } \\
\text { TRABAJADORES }\end{array}$} & Hasta 10 trabajadores & $4,9 \%$ \\
\hline & De 10 a 50 trabajadores & $8,0 \%$ \\
\hline & Más de 50 trabajadores & $19,0 \%$ \\
\hline \multirow{4}{*}{ FORMA JURÍDICA } & Sociedad Limitada & $5,3 \%$ \\
\hline & Sociedad Anónima & $1,8 \%$ \\
\hline & Empresas de Economía social & $14,4 \%$ \\
\hline & Otras & $4,7 \%$ \\
\hline
\end{tabular}

$6 \quad$ Club de Excelencia en Sostenibilidad (2013). 


\begin{tabular}{|l|l|l|}
\hline \multirow{4}{*}{ SECTOR } & Agroalimentario & $8,5 \%$ \\
\cline { 2 - 3 } & Industrial & $2,5 \%$ \\
\cline { 2 - 3 } & Construcción & $1,0 \%$ \\
\cline { 2 - 3 } & Comercio & $5,5 \%$ \\
\cline { 2 - 3 } & Servicios & $6,1 \%$ \\
\hline
\end{tabular}

Base: Total de empresas.

Con el objeto de valorar el impacto de la ISR en la estructura financiera de las empresas de ES se ha constatado que el porcentaje medio de presupuesto destinado a tales inversiones asciende al 10\%, frente al 8,7\% para el total de empresas. En cuanto a los responsables de la toma de decisiones para realizar este tipo de inversiones, parece ser que en la mayor parte de los casos las toman el equipo directivo de la empresa $(52,2 \%)$.

En conclusión, el compromiso de las empresas de ES con sus grupos de interés, es superior en cuanto a las medidas de responsabilidad hacia el consumidor, y en cuanto a la realización de ISR, superando sobradamente el nivel constatado para el conjunto de empresas de la CV. Por el contrario el control de la cadena de proveedores-suministradores son medidas de responsabilidad social inferiormente contempladas por la ES valenciana, con casi 5 puntos porcentuales respecto del total de empresas. La H3 es por lo tanto, sólo aceptada parcialmente, es decir, considerando las matizaciones realizadas.

Gráfico. 9. Impacto de las responsabilidades de la ES con sus grupos de interés respecto total de empresas de la CV

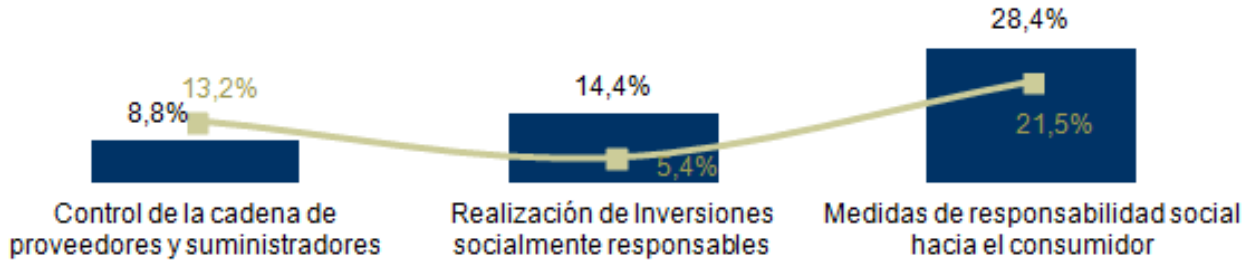

Fuente: Elaboración propia. 


\section{Las prácticas de buen gobierno en las empresas valencianas de economía social}

Los Códigos de Buen Gobierno son una medida de RSE de muy débil incidencia entre las empresas de ES de la CV, puesto que sólo el 0,5\% de las mismas declaran tenerlos. Un gran reto para la ES, si se compara con el 15,2\% del total de empresas valencianas que indican disponer de alguno de los mismos. Su incidencia es superior en el caso de las empresas de mayor tamaño $(28,7 \%)$, las sociedades anónimas $(20,0 \%)$, y en los sectores de la construcción $(21,5 \%)$ e industrial $(15,1 \%)$.

Tabla. 16. Empresas de la CV que cuentan con un Código de Buen Gobierno.

\begin{tabular}{|c|c|c|}
\hline \multirow{3}{*}{$\begin{array}{l}\text { SEGÚN NÚMERO DE } \\
\text { TRABAJADORES }\end{array}$} & Hasta 10 trabajadores & $15,4 \%$ \\
\hline & De 10 a 50 trabajadores & $10,8 \%$ \\
\hline & Más de 50 trabajadores & $28,7 \%$ \\
\hline \multirow{4}{*}{ FORMA JURÍDICA } & Sociedad Limitada & $15,7 \%$ \\
\hline & Sociedad Anónima & $20,0 \%$ \\
\hline & Empresas de Economía social & $0,5 \%$ \\
\hline & Otras & $1,5 \%$ \\
\hline \multirow{5}{*}{ SECTOR } & Agroalimentario & $3,4 \%$ \\
\hline & Industrial & $15,1 \%$ \\
\hline & Construcción & $21,5 \%$ \\
\hline & Comercio & $10,0 \%$ \\
\hline & Servicios & $16,3 \%$ \\
\hline
\end{tabular}

Base: Total de empresas

Se trata de Códigos de Buen Gobierno implantados mayoritariamente, en el $49,5 \%$ de los casos, a lo largo de la última década, estando el 56,4\% de los mismos verificados, a través de auditoría externa o monitorización independiente en el $62,3 \%$ de los mismos.

Respecto a las medidas de Buen Gobierno adoptadas por las empresas valencianas, hay que señalar que destacan con mayor incidencia, aquellas que tienen que ver con la mejora de la transparencia en la gestión, con un 70,2\%. En cuanto a aspectos relacionados directamente con el órgano de gobierno, se constata que la existencia de comités consultivos independientes se adopta en un $18,5 \%$. Se especifica, en un porcentaje del $26,8 \%$, que existe independencia de los consejeros o comisionados. Así mismo, se subraya que existen medidas que limitan la concentración de poder en un $33,2 \%$.

Por otro lado, las medidas que inciden en la transparencia retributiva se alcanzan un peso del $69,1 \%$. Las medidas que afectan a la transparencia contable hacia los socios se sitúan en el $48,9 \%$. La existencia de limitaciones a las retribuciones de los consejeros o comisionados se sitúa en un nivel del $18,3 \%$. Por 
lo que toca sobre la existencia de medidas de participación de los trabajadores en la empresa, se reconoce con una incidencia del 20,3\%. En cuanto a la paridad de género en los Consejos de Administración se reconoce su implementación en un $7,9 \%$.

Gráfico. 10. Medidas de Buen Gobierno implementadas por las empresas de la CV

Base: Empresas que disponen de un Código Ético o de Buen Gobierno

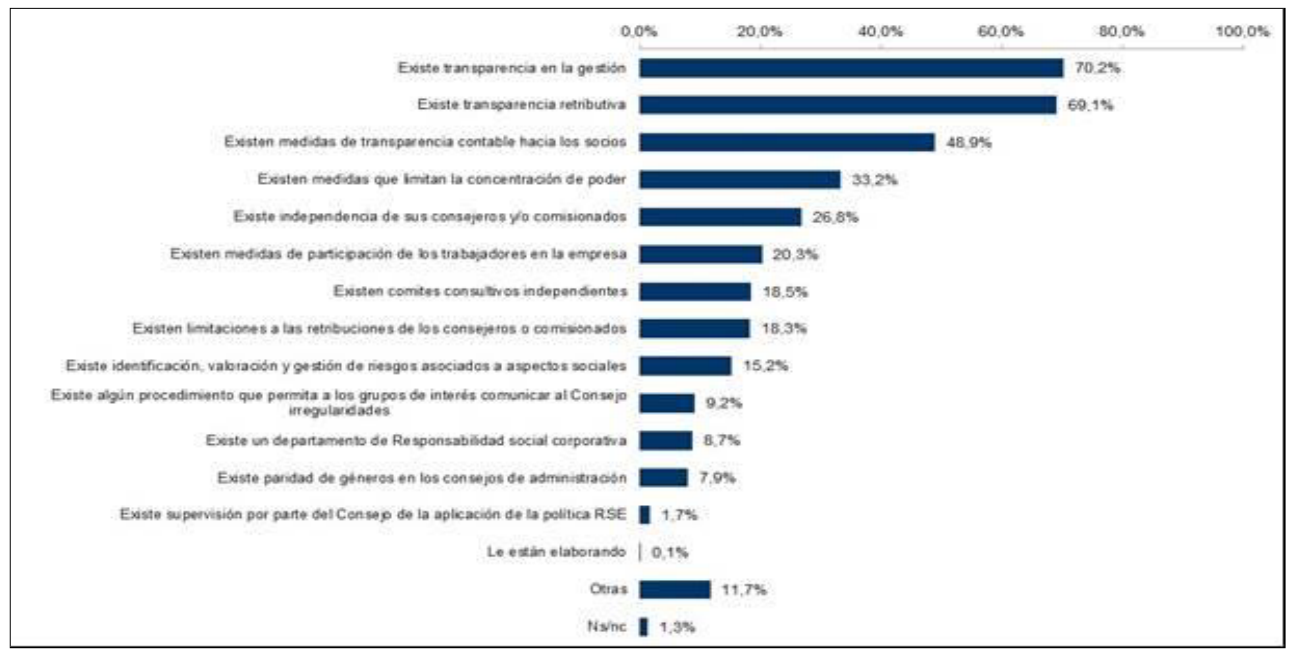

Nota: Respuesta múltiple.

Con un porcentaje del $9,2 \%$ se evidencia que existe algún procedimiento que permite a los grupos de interés comunicar al Consejo irregularidades. En cuanto a la existencia de un departamento de RSE únicamente se reconoce en un porcentaje del 8,7\% de empresas. La existencia de supervisión por parte del Consejo de la aplicación de la política de RSE se da en un 1,7\%. Por otro lado, se constata en un porcentaje del $15,2 \%$ que existen medidas que permiten la identificación, valoración y gestión de riesgos asociados a aspectos sociales.

A tenor de los resultados evidenciados, la $\mathrm{H} 4$ es rechazada.

El gráfico siguiente recoge a modo de conclusión la comparativa de las prácticas de RSE de las empresas de ES, y el total de empresas de la CV. Como se observa las empresas de Economía Social se hallan superiormente comprometidas (con diferenciales superiores a 8 puntos ) respecto del total de empresas de la Comunidad en la práctica totalidad de los ítems que conforma la RSE interna, como es el compromiso social, laboral y medioambiental. No obstante, acusan un diferencial negativo en el área de Buen Gobierno, a pesar de la asunción de principios de gestión y dirección acordes con la RSE, como es el principio democrático, entre otros. Este diferencial es especialmente significativo en el terreno de la filantropía empresarial, paradójico en un sector institucional cuna de la filantropía, la solidaridad, y el voluntariado (Sajardo, 2012). 
Gráfico 11. Comparativa compromiso RSE de ES respecto del total de empresas de la CV.

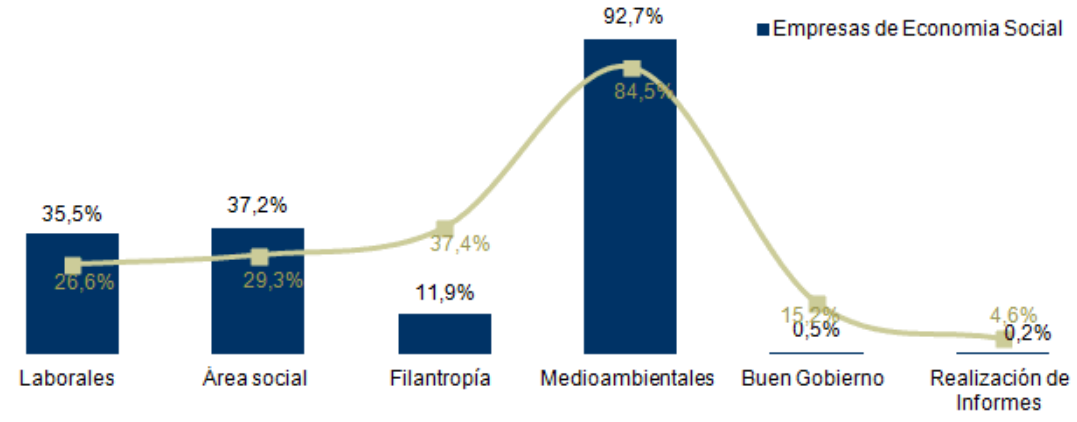

Saldo ES:

$+8,9 \%$

$+7,9 \%$

$-25,5 \%$

$+8,2 \%$

$-14,7 \%$

$-4,4 \%$

\section{A modo de conclusión}

El profundo convencimiento de la necesidad de llegar a acuerdos sobre ética global en materia de desarrollo sostenible, de lucha contra el cambio climático, de mejora de la transparencia, de reducción de la desigualdades, de comportamiento ético etc, se halla en la agenda institucional a nivel mundial, ejerciendo de guía clara para el tejido productivo, incrementalmente consciente de la correlación indisoluble entre sostenibilidad y competitividad, en la edificación de otra manera de hacer empresa, y por ende de economía y de sociedad.

La propia naturaleza y principios de actuación de las empresas de ES en general, y particularmente de las cooperativas, las erigen como exponentes representativos de una empresa responsable, modelo y vanguardia de la nueva manera de hacer economía, donde sus acciones atienden al resultado económico y financiero, pero también al social y al ambiental. En la ES se generan unos vínculos y valores sociales superiores a cualquier otro tipo de empresas, y por lo tanto cuentan con mayor potencial para la adopción de prácticas de RSE.

Este trabajo se ha dedicado al estudio del modelo de RSE interna seguido por las empresas de ES de la CV, y su comparativa con las prácticas de RSE del total de empresas valencianas, evidenciando su superior compromiso con la RSE interna.

Así, se muestra que las empresas valencianas de ES son superiormente responsables en la RSE interna, con diferenciales positivos superiores a 8 puntos porcentuales en el área laboral, social y medioambiental. Todo ello se halla en coherencia con los valores que subyacen a estas empresas, y en coherencia con los principios que informan su funcionamiento, y que son recogidos, en el ámbito de las cooperativas, en virtud de los Principios Cooperativos.

Sólo en el área de Buen Gobierno empresas de ES son inferiormente responsables respecto del conjunto de empresas de la Comunidad, con un significativo ratio negativo del $14,7 \%$. Ello resulta especialmente llamativo a tenor 
de uno de los postulados básicos de la ES, como es el principio democrático, $2^{\circ}$ Principio, (ACI, 1995).

La comunicación de la RSE es también inferiormente realizada por las Economía Social Valenciana, con un diferencial de $-4,4 \%$. La RSE externa, conformada por la denominada filantropía externa parece también ser un área de menor compromiso por las empresas valencianas de Economía Social, con un diferencial del $-25,5 \%$.

\section{Referencias bibliográficas}

ACI (2007) Statement on the Co-operative identity, documento consultado en: http://www.ica.coop/coop/principles.html.

ACI-Américas (2010) Responsabilidad Social Cooperativa.

ACI (1995) Declaración sobre la identidad cooperativa, Manchester, 23 de septiembre 1995.

Arcas, N. y Briones, A.J. (2009) Responsabilidad Social Empresarial de la Economía Social. Valoración de la misma en las empresas de la Región de Murcia, Ciriec-España. Revista de Economía, Pública, Social y Cooperativa, no 65, pp. 143-161.

Arana, S. (2010) La Economía Social en la vanguardia de la Responsabilidad Social de la Empresa, Gezki, no 6, pp.71-91.

Belhourai, A., Buendía, I., Lapointe, M-J. y Tremblay, B. (2005) La responsabilidad social de las empresas: ¿un nuevo valor en las cooperativas?, Ciriec-España. Revista de Economía, Pública, Social y Cooperativa, $\mathrm{n}^{\circ}$ 53, pp. 191-208.

BOE-A-3868 (2008): Real Decreto 221/2008, de 15 de febrero, por el que se crea y regula el Consejo Estatal de Responsabilidad Social de las Empresas. Documento Consulado en https://www.boe.es/buscar/act.php?id=BOE-A-2008-3868.

Castilla, F. y Gallardo, D. (2014) La revelación social en sociedades cooperativas: una visión comparativa de las herramientas más utilizadas en la actualidad, REVESCO. Revista de Estudios Cooperativos, $\mathrm{n}^{\mathrm{o}}$ 114, pp. 7-34. DOI: 10.5209/rev_REVE.2014.v114.44291.

Carrasco, I. (2007) Corporate Social Responsibility, values and cooperation, International Advances in Economic Research, $\mathrm{n}^{\circ}$ 13, Vol. 4, pp.454-460.

Ceballo, A.I. (2005) Responsabilidad social: un valor añadido para las empresas, un criterio de discriminación positiva para los consumidores, Ciriec-España. Revista de Economía, Pública, Social y Cooperativa, no 53 , pp.65-77.

CEPES (2007) Manual para el tutor del Programa RSE.COOP. Documento consultado en: http://www.cepes.es/listado.cfm?padre=389\&idSeccion=390\&idsec $=$ sec $\_11$.

CEPES (2009) Anuario 2007-2008, documento consultado en: http://www.afundacion.org/docs/socialia/anuario_economia_social_2007_2008.pdf.

Collado, J.L. (2006) La Responsabilidad Social Corporativa y las cooperativas: aspectos y formulaciones comunes, XI Jornadas de Investigadores de Economía Social y Cooperativa, CIRIEC-España-CECOOP, Santiago de Compostela.

Comisión Europea (2001) Libro Verde. Fomentar un marco europeo para la responsabilidad social de las empresas, COM (2001) 366 Final. Documento consultado en:

http://www.europarl.europa.eu/meetdocs/committees/deve/20020122/com(2001)366_es .pdf. 
Comisión Europea (2011) Estrategia Renovada de la Unión Europea sobre Responsabilidad Social de las Empresas. COM (2011) 681 Final, documento consultado en:

http://ec.europa.eu/enterprise/policies/sustainable-business/corporate-social responsibility/index_en.htm.

Curto, M. (2012) La Responsabilidad Social Interna de las empresas, Cuadernos de la Cátedra de Responsabilidad Social de la Empresa y Gobierno Corporativo, IESE.

Iturrioz, J., Mateu, J.L. y Valor, C. (2005) La implicación de las sociedades cooperativas de crédito y las cajas de ahorros en los productos y servicios financieros socialmente responsables, Revista Vasca de Economía Social, n 2005-1, pp. 63-84.

Iturrioz, J., García, J.C., Mateu, J.L. y Palomo, R. (2011) La percepción sobre la responsabilidad social en las sociedades cooperativas de trabajo asociado y las sociedades laborales: un análisis en el ámbito de la Ciudad de Madrid. REVESCO. Revista de Estudios Cooperativos, $\mathrm{N}^{\mathrm{o}}$ 104, pp. 102-124. DOI: 10.5209/rev_REVE.2011.v104.4.

De Castro, M. (2005) La Responsabilidad Social de las Empresas, o un nuevo concepto de empresa, Ciriec-España. Revista de Economía, Pública, Social y Cooperativa, $\mathrm{n}^{\mathrm{o}}$ 53,pp. 29-71.

De Castro, M. (2006) Las empresas de economía social y la responsabilidad social corporativa, Papeles de Economía Española, n 108, pp.92-104.

Díaz, M. y Marcuello, C. (2008) Economía Social y Responsabilidad Social Corporativa. XI Jornadas de Economía Crítica, Bilbao, 27-29 de marzo del 2008.

Epstein, E. (2007) The Good Company: Rethoric or Reality? Corporate Social Responsability and Business Ethics Redux, American Business Law Journal, vol. 44, pp. 207-222.

Forética (2015) Informe 2015, Ciudadano consciente, empresas sostenibles, documento consultado en: http://foretica.org/informe_foretica_2015.pdf.

Gallardo, D. y Castilla, F. (2014) Modelo de Gestión para la Responsabilidad Social en Cooperativas, Revista de Economia Industiral, $\mathrm{n}^{\circ} 369$, pp.139-149.

Jauregui (2015) De la Responsabilidad Social Empresarial a la Economía del Bien Común, documento consultado en http://diarioresponsable.com/portada/opinion/19780-de-larse-a-la-economia-del-bien-comun-ramon-jauregui.html.

Martín, S., Lejarriaga, G. e Iturrioz, J. (2007) La naturaleza del capital social como aspecto diferenciador entre las sociedades cooperativas y las sociedades laborales, CiriecEspaña. Revista de Economía, Pública, Social y Cooperativa, no 58, pp.59-82.

Mozas, A. y Poyatos, R. (2010) La Responsabilidad Social Corporativa y su paralelismo con las sociedades cooperativas, REVESCO. Revista de Estudios Cooperativos, $\mathrm{n}^{\circ} 103$, pp.75-100.

Mugarra, A. (2001) Responsabilidad y Balance Social hoy en día: Un reto para las Cooperativas. Ciriec-España. Revista de Economía, Pública, Social y Cooperativa, ${ }^{\circ}$ 39 , pp. $25-50$.

Mugarra, A. (2005) Memoria de sostenibilidad. Una propuesta adaptada para las cooperativas de enseñanza del País Vasco, Ciriec-España. Revista de Economía, Pública, Social y Cooperativa, $\mathrm{n}^{\circ}$ 53, pp. 306-333.

Palomo, R. y Valor, C. (2004) El activismo de los socios como catalizador de la RSE: aplicación a las organizaciones de participación", Ciriec-España. Revista de Economía, Pública, Social y Cooperativa, nº 50, pp.167-190. 
Parlamento Europeo (2009) Informe sobre Economía Social (Informe Toia), documento consultado en: $\quad$ http://www.europarl.europa.eu/sides/getDoc.do?pubRef=//ep//nonsgml+report+a6-2009-0015+0+doc+pdf+v0//es.

Parlamento Europeo (2013) Resolución del 2 de julio sobre la contribución de las cooperativas a la salida de la crisis (2012/2321(INI)).

Perdiguero, T.G. (2003) La responsabilidad social de las empresas en un mundo global, Ed. Anagrama, Barcelona.

Perdiguero, T.G. y García Reche, A. (dirs) (2014) Cultura, prácticas y políticas de Responsabilidad de las empresas del IBEX-35, Observatorio de RSE de UGT.

Resolución Parlamento Europeo Sobre la responsabilidad social de las empresas: promover los intereses de la sociedad y un camino hacia la recuperación sostenible e integradora (2012/2097(INI)), documento consultado en: http://www.europarl.europa.eu/portal/es.

Sáez, F.J, González, F. y Sánchez, M. (2003) Cooperativas, sociedades laborales y mutualidades de previsión social: 25 años de progreso de la Economía Social de mercado bajo la constitución, Ciriec-España. Revista de Economía, Pública, Social y Cooperativa, $\mathrm{n}^{\circ}$ 47, pp.175-198.

Sajardo, A. y Serra, I. (2008) La Responsabilidad Social Empresarial y la Ciudadanía Corporativa en la Comunidad Valenciana, Ed. Tirant Lo Blanch, Valencia.

Sajardo, A. (2009) (dir) La reponsabilidad social empresarial interna de las empresas españolas, ed. Tirant lo Blanch. Valencia.

Sajardo, A. (2012) Análisis económico del Sector No Lucrativo: aspectos económicos del voluntariado", ed. Tirant lo Blanch. Valencia.

Sajardo, A. (2010) (Dir) La dimensión interna de la RSE en España, Ed. Tirant Lo Blanch, Valencia.

Sajardo, A. (2015) Diagnóstico de las prácticas de responsabilidad de las empresas de la Comunidad Valenciana, Dirección General de economía, emprendimiento y cooperativismo, Estudios Económicos. Consellería de Economía, Generalitat Valenciana.

Sajardo-Moreno, A. y Chaves-Sajardo, R.J. (2016) El modelo de RSE de las empresas de Economia Social de la Comunidad Valenciana, comunicación presentada al Congreso XVI CIRIEC-España, Valencia.

Valor, C. (2005) Inversión Socialmente Responsable en las entidades financieras de Economía Social, Universidad San Pablo-CEU, Madrid.

Valor, C., Iturrioz, J., Palomo, R. y Mateu, J.L. (2007) Socially Responsible Investments among Savings Banks and Credit Unions: Empirical Findings in the Spanish Context, Annals of Public and Cooperative Economics, Vol. 78, pp. 301-326.

Vargas, A. y Pelayo, Y. (2000) La práctica de los principios cooperativos en las Almazaras cooperativas de Huelva, XIV Congreso Nacional de AEDEM.

Vargas, A. (2001) Los emprendedores y los valores cooperativos. Consideración del papel de la información en el desarrollo de redes de empresas en democracia, en Moyano, J. (Coord) La sociedad cooperativa: un análisis de sus características societarias y empresariales, Universidad de Jaén.

Vargas, A. y Vaca, R.Ma . (2005) Responsabilidad Social Corporativa y Cooperativivismo: Vínculos y potencialidades, Ciriec-España. Revista de Economía, Pública, Social y Cooperativa, $\mathrm{n}^{\mathrm{o}}$ 53, pp. 241-260.

Fe de erratas: Este artículo estuvo publicado durante el periodo comprendido entre el 22 de noviembre de 2017 y el 21 de diciembre de 2017 con una errata atribuible al equipo editorial de la revista porque se le asignó al autor Rafael J. Sajardo-Chaves una dirección de correo electrónico que no era suya. 